\title{
Importance of Forensic Investigation in Explosion: A Case study
}

\author{
Surendra Kumar, Pradeep Jain and Mukesh Sharma*
}

State Forensic Science Laboratory, Jaipur, Rajasthan, India

*Corresponding Author: Mukesh Sharma, State Forensic Science Laboratory, Jaipur, Rajasthan, India, Tel: +919460986307; E-mail: mksphy@gmail.com

Received date: August 29, 2016; Accepted date: October 26, 2016; Published date: October 28, 2016

Copyright: (c) 2016 Kumar S, et al. This is an open access article distributed under the terms of the Creative Commons Attribution License, which permits unrestricted use, distribution, and reproduction in any medium, provided the original author and source are credited.

\begin{abstract}
In India, the forts and fortresses are historical heritage and symbol of grandeur, dignity and strength of our vibrant past. Rajasthan is the most visited place by foreigners in India to feel and explore this heritage. All these forts and fortresses were equipped with every kind of war wares \& weapons, which can be found or witnessed decades later, nowadays too and gun powder was one of the essential commodities of warfare. The unutilized gun powder in these forts brings a problem as no one knows about its whereabouts of storage as these forts and fortresses got abandoned on their own and this causes accidental explosions.

Such an interesting in forensic point of view incident was reported in the fortress of village Jasaana where some arc welding for the modernization work in the fortress was being done and a massive explosion occurred. Our team of expert visited the spot of occurrence, in forensic point of view, calculated the amount of explosive materials and level of explosion. On the basis of our observations we concluded that this explosion might have been caused by gunpowder. Through this article we tried to put light on the features and characteristics phenomenon of gun powder explosion and we have performed first ever a forensic attempt to estimate the approximate amount of gun powder that got exploded.
\end{abstract}

Keywords: Forensic investigation; Crime scene; Forensic explosion; Gun powder

\section{Introduction}

There is a very rich history of gun powder in whole world after originating in China but lost its dignity after invention of smokeless powder. Before the entrance of gunpowder in India, majority of wars were fought with swords and valour of fighters but gun powder changed whole scenario when it was first used in first battle of Panipat on 21 April 1526 in India which gave way to Mughal dynasty to establish in India. After that it become essential part of every fort and played the same role in its own time as nuclear weapons are playing in present era [1-3].

Explosions often present complex and difficult circumstances to investigate. Normally, these incidents are committed at the convenience of a perpetrator who has thoroughly planned the criminal act and has left the crime scene long before any official investigation is launched. But in this study it was an accident, on the basis of forensic evidences, we have proved whole happening [4,5].

Visiting this type of crime scene, forensic expert must have fundamental concept of explosive, pattern of explosion, residue of explosion and pattern of damage. The contribution of a forensic scientist is only one aspect of a comprehensive and difficult investigative process that must establish a motive, the modus operandi, a suspect or it was an accident [6,7].

In general, explosives are classified as high and low explosives, according to the type and velocity of the reaction involved. High explosives as detonating charges, are subdivided into two groups, primary and secondary explosives, according to their function in the explosion.

The primary explosives, which include lead azide and lead styphnate, are used to start the explosion as in the blasting cap [8]. Secondary explosives, which include nitroaromatics and nitramines are common at military sites than primary explosives. If the explosive decomposition reaction moves through the charge faster than the speed of sound in the unreacted medium, it is termed as detonation.

However, if it moves slower, it is termed as deflagration [9]. Explosives that detonate are characterized as high explosives. Due to very high rate of reaction and generation of high pressure on explosion, high explosives are suitable for shell and bomb fillers.

High explosives are subdivided depending upon their sensitivity to external stimulations into

- Primary explosives,

- Secondary explosives and

- Tertiary explosives.

Primary high explosives are very sensitive and they easily explode by an application of fire, spark, impact and friction, and hence are dangerous to handle. These explosives are generally used in primers, detonators and percussion caps. In comparison to primary explosives, secondary high explosives are relatively insensitive to mechanical shock and flame [10,11]. Military and civil explosives are used for military applications and commercial purposes, respectively, as depicted in Figure 1 [10]. 


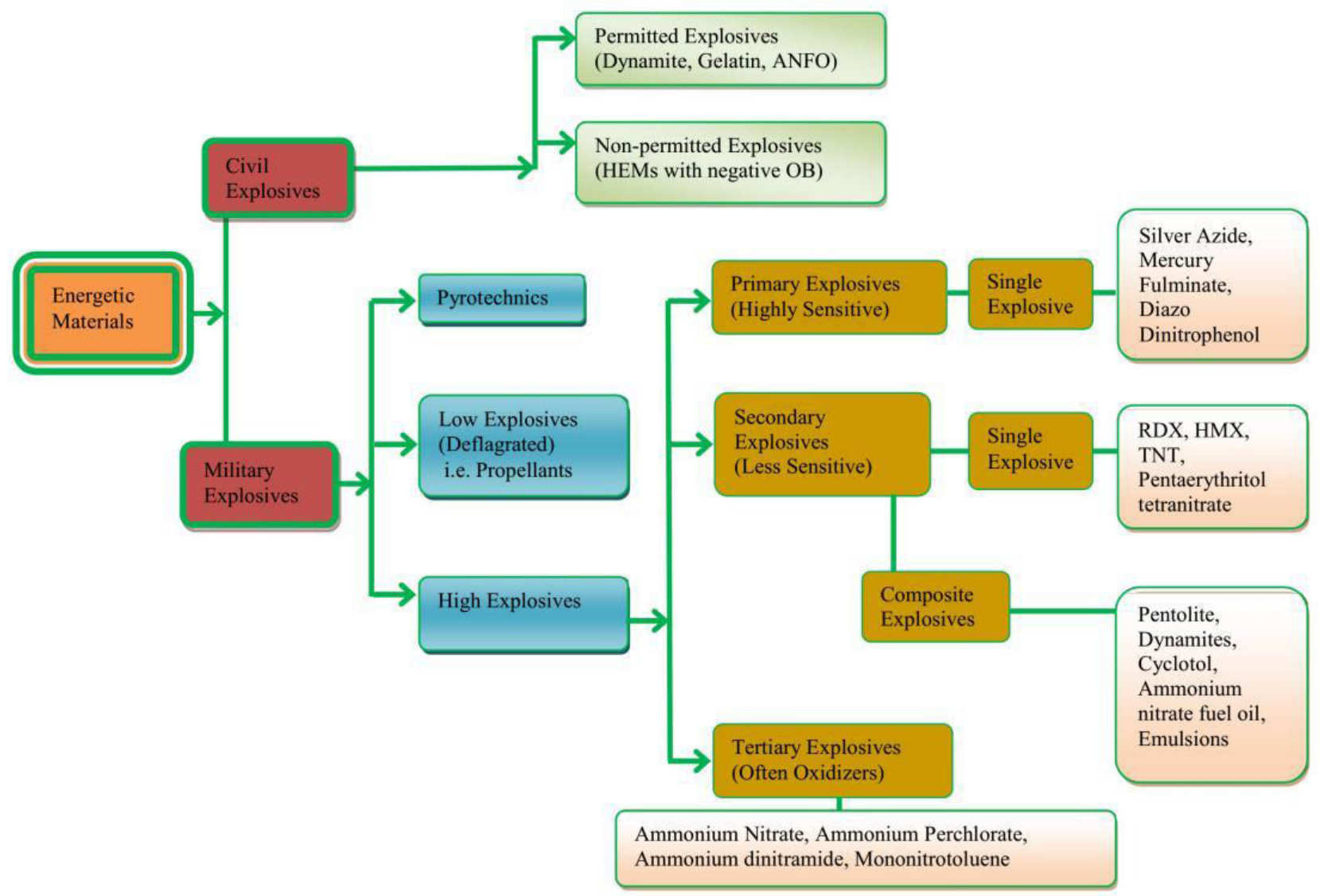

Figure 1: Classification and grouping of explosives.

All high explosives and blasting agents detonate when properly initiated, whereas low explosives or black powder deflagrate. Low explosives are normally known as propellants as they undergo deflagration slowly at rate of 1000 feet per second [6]. Gun powder or black powder and smokeless powder are some of the typical low explosives known. There are many compositions of black powder with the common form containing a mechanical mixture of potassium or sodium nitrate with sulphur and finely ground charcoal [12].

\section{Material and Methods}

Gun powder also known as black powder is the earliest known explosive and is a mixture of potassium nitrate (salt peter), sulphur and charcoal. Sulphur and Charcoal acts as fuel while potassium nitrate as an oxidizer. Ratio of the ingredients is not well defined and so the specific gravity of gun powder is in the range 1.70 to 1.82 and $\mathrm{pH}$ 6.0-8.0 and is classified as low explosive which deflagrate instead of detonate. Gun powder produces average $270 \mathrm{cc}$ gas per gram on deflagration [4]. It just burns in open but its burning speed increases with pressure so it can explode closed vessel (container). The energy of gun powder is 3 mega joules per kilogram in comparison of 4.7 mega joules per kilogram of TNT.

\section{Observations and Estimation}

An incident of explosion was reported while labourers were working in an old fortress with an electrical arc welding machine on the door of a room of fortress (Figure 2). The incident took the life of two persons while two others got seriously injured.

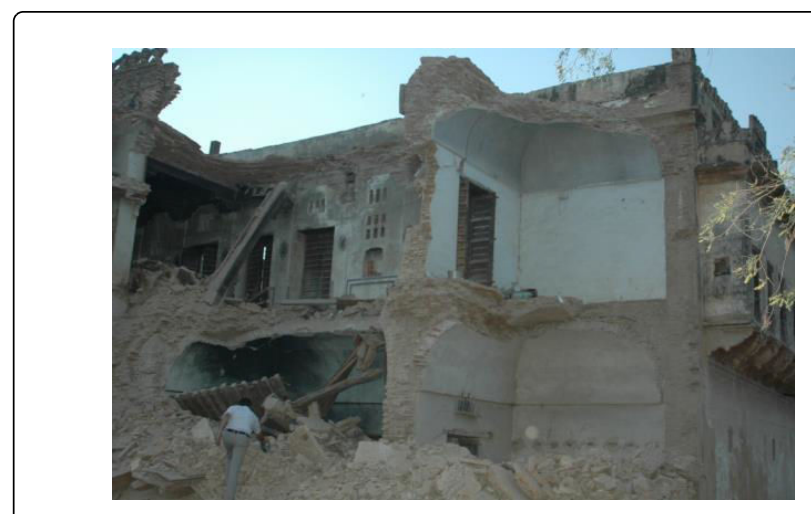

Figure 2: Team visited after explosion and able to solve the happening on the basis of residual parts. 
The back side wall of two double storey room collapsed and double panel wooden bulky door and bodies of deceased flew away approximately $50 \mathrm{ft}$ from its initial positions. Inside the room a jet black coloured hard residual layer along with globules of the same colour \& nature was detected starting from north-western bottom corner to the roof \& maximum density of it was on western wall, northern wall and remaining part of the roof. The room was facing toward north and having dimension of $16 \times 10 \times 12 \mathrm{ft}$. The eastern wall was least affected and southern wall collapsed completely. The double panel wooden door got fragmented during flight and scattered over the open yard in front of the room. Neither crater was found inside the room nor the remaining walls got any damage i.e. no splinters were detected. No gas cylinder was found inside the room ruling out explosion caused due to LP gas. Now mystery of explosion got darkened but jet black residue and peculiar gun powder burning like odour was quite indicative of possible villain slept silently for decades in north-western corner of the room (Figure 3). First of all physics came front to help by supplying fact that to collapse wall and blowing away the door, minimum 3 psi (pounds per square inch) pressure is required inside the room for any hard construction of now-a-days. Though fortress is 160 years old but its strength can be compared with modern day cement supported walls due to thickness of walls and small size of burnt clay bricks of previous century adhered by some lime stone preparation generally used in old buildings, hence pressure can be assumed 3 psi.

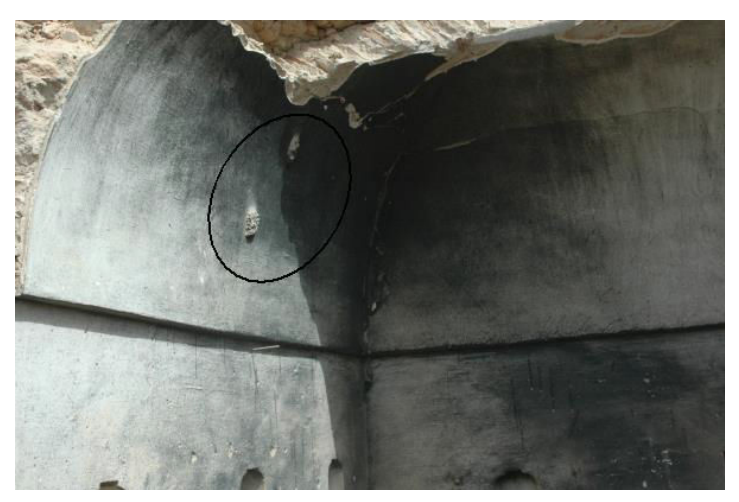

Figure 3: Remaining part of the building, as shown in figure with black circle welding material, some smouldering hot metal or welding mixture was found.

Three psi pressure excess to atmospheric pressure results into the value 1.2 atmospheric pressure on conversion. To generate this pressure inside the room volume of gas required is pressure multiplied by the volume of room in cubic feet. Hence the required amount of gas should be either blown in abruptly inside the room or generated inside the room. One gram of black powder yields $718 \mathrm{cal}$ of heat, $270 \mathrm{cc}$ of permanent gas, and roughly a half-gram of solid residues, proving that transformation is inefficient compared to smokeless powder [4]. By applying basic physics and chemistry of the explosion we have first ever estimated the amount of the Gun Powder present at the time of explosion in that affected room. The simple mathematical estimation of total consumed Gun Powder is as detailed below:

- Pressure excess required to demolish the construction $=3$ psi (pound per square inch)
- One psi=0.068 Atmospheric pressure, hence 3 psi pressure $=0.20$ atmospheric pressure

- So total pressure inside the room $=$ pressure excess + atmospheric pressure $=0.2+1.0=1.2$ atmospheric pressure

- Total Volume of room $=(16 \times 10 \times 12)$ as room dimensions were $\mathrm{L}=16$ feet, Width $=10$ feet and Height $=12$ feet

- To create 1.2 atmospheric pressure inside the room, required amount of gas $=$ pressure required $\times$ volume of room $=(16 \times 10 \times$ 12) $\times 1.2=2304$ feet, as in 1 feet $=28.317$ litre

- So total volume in litres $=65242.39$ litre

- One g Gun Powder produces=270 cc gas so $1 \mathrm{~kg}$ Gun Powder will produces $=270$ litres gas on burning.

Hence Total Quantity of the Powder might be $=65242.39 / 270=241.64$ $\mathrm{kg}$. Gun Powder might be present at the time of explosion in the room where explosion was occurred is $241 \mathrm{~kg}$ approximately.

The experts suggested to the Investigating Officer (IO) to send the samples for examination in forensic laboratory from walls to ascertain the presence of gun powder [11]. After two-three days of the incident the IO reported that during investigation it was revealed that approximately 200 to 250 kilogram of gun powder was stored in the room by inheritance, which was a verification of our estimated calculations of Gunpowder explosion.

\section{Discussion}

At this juncture of time, we are able to visualize or reconstruct the whole incident and our calculation of explosion also verifies the level of explosion and type of explosion. The gun powder was stored loose or in some flammable bag/bags in north-western corner of the room. Due to open material present at the incident place no crater and no damage was observed to remaining adjacent walls which might be possible due to splinters etc. The gun powder was unintentionally spread towards the door by some humanoid or biological activities, while the door was getting its strength back through welding, some smouldering hot metal or welding mixture part of the rod came in contact with the gun powder underneath the door worked as detonating device to the powder material and whole havoc happened giving two persons untimely demise while two others seriously injured and a great damage to this historical heritage. This result depicts the category of Low Explosive (deflagrated) because the main content of gun powder is potassium nitrate, as shown in Figure 1.

Through this study we are approximately calculated the amount of the powder material available at the time of explosion and level of damage was explained, which created a path to the investigating agency and whole process of investigation was converted into an accident. On behalf of our study, we may conclude to avoid gunpowder type of explosions in fort and fortress by designed building to store the explosive in wooden barrels for safety. The proper symbol and sign should be used for the area in the fort and fortress, where the low explosive materials being preserved.

\section{Acknowledgement}

Authors are thankful to the Director, State FSL, Jaipur for encouragement and Prof B. L. Ahuja, Professor in Physics, Chairman, Faculty of Science, M L Sukhadia University for fruitful discussion. 
Citation: Kumar S, Jain P, Sharma M (2016) Importance of Forensic Investigation in Explosion: A Case study. J Forensic Res 7: 347. doi:

Page 4 of 4

\section{References}

1. http://www.americanfirearms.org/gun-history/

2. Kenneth C (2003) Firearms: A Global History to 1700. Cambridge University Press, Cambridge, UK. pp: 32-33.

3. Kenneth C (2003) Firearms: a global history to 1700. Cambridge University Press, Cambridge, UK. pp: 58.

4. Fadala S (2006) The Complete Blackpowder hand book, Krause Publications, USA.

5. Reno J, Marcus D, Leary ML, Samuels JEA (2000) Guide for Explosion and Bombing Scene Investigation. National Institute of Justice, Washington DC, USA.

6. Saferstein R (2007) Criminalistics: An Introduction to Forensic Science, (9th Edn), Pearson Education, New Jersey, USA.
7. Moore DS (2007) Recent Advances in Trace Explosives Detection Instrument. Sens Imaging 8: 9-38.

8. Martin RJ, Reza A, Anderson LW (2000) What is An Explosion? A Case History of an Investigation for the Insurance Industry. J Loss Prevent Proc 13: 491-497.

9. Yinon J, Zitrin S (1993) Modern Methods and Applications in Analysis of Explosives. John Wiley and Sons, London, UK.

10. Agarwal JP (2010) High Energy Materials: Propellants, Explosives and Pyrotechnics. Wiley-VCH Verlag GmbH \& Co, Weinheim, Germany.

11. Pradeep J (2013) Electronic properties of some energetic materials. PhD thesis, Udaipur: M L Sukhaida University, Rajasthan, India.

12. Bajaj A, John C, Singh M (2016) Explosive Post Blast Analysis: A Case Study. Eur J Forensic Sci 3: 50-54 